\title{
Towards the Efficient Communication of Political Messages in Thailand: An Empirical Investigation
}

\author{
Wilaiporn Laohakosol, *John Walsh \\ Shinawatra International University, Bangkok, Thailand \\ *jcwalsh@siu.ac.th
}

\begin{abstract}
Models of consumer behavior generally posit an eclectic paradigm in which diverse elements may have an influence on an individual consumption decision. These elements might include personal experience, bias, the influence of family members and peer groups. This understanding of human behavior has been relocated from the commercial realm to the political realm with a view to helping to understand how the formation of people is voting intentions might take place and how it might be influenced. Since politics consists of a series of competing ideologies contending for the scarce resource of votes with a view to aligning state policies and the distribution of state resources along the lines of the manifesto on which a party is fighting, it follows that politicians will wish to use communication strategies to encourage as many eligible individuals as possible to vote for their policies. To date, in Thailand, most forms of political communication have been based on establishing personal contact and, hence, a form of personal relationship based on personality rather than policies. This situation is beginning to change, there is a need for those involved in determining the nature, and extent of political communications to understand which channels are appropriate for which groups of voters and which voters will not be influenced by any medium or message. Using a quantitative sample of 400 voters in four provinces of Thailand, this paper provides evidence to show that the degree to which people pay attention to political communications and to different channels varies in reasonably predictable fashions. This will enable political institutions and parties to work together to determine good and effective means of communicating their policies to the public in ways which will strengthen democratization in the country.
\end{abstract}

Keywords: Political participation, channels of political communication, ideology

\section{Introduction}

The first General Election in Thailand was held on November 15 th 1933 (2476 Buddhist Era - B.E.) with 78 candidates elected as Members of Parliament (MPs), sometime after the 1932 revolution that brought about the end of the Absolute Monarchy in Siam. This was an indirect election that involved sub-district (Tambon) representatives elected as Members to the House of Representatives. The first direct election was held on November 7, 1937 (2480 B.E.) and this is the first election for which graphic political messages or communications are available (Appendix 1). The 23 ${ }^{\text {rd }}$ election was held on December 23, 2007 (2550 B.E.) with 480 members elected (400 constituency members and 80 party-list members). Rules and regulations regarding processes, qualifications of voters and candidates, together with the governmental body in charge of organizing the general election, were changed or amended so as to operate efficiently and be responsive to the political environment of the country and the modernized, democratic countries of the western world, rather than to suit the convenience of the political and electoral system (Nelson, 2009). In investigating the 2007 general election, it is wondered whether the rational choice theory of Downs, which stated that significant elements of political life could be explained in terms of voter self-interest (Downs, 1957), would be an appropriate description of the process or would other variables such as economics, education, culture, values, opinions, beliefs (traditional or religious), geographical boundaries be more relevant? Rational choice theory is derived from economics and posits the idea that individuals will make a decision concerning their actions in the light of perfect information and based on maximizing their own particular returns. Such an idea informs Weber and was extended by such as Mauss as part of a socialized exchange value theory of behavior. It has been argued (e.g. Zafirovski, 1998) that proponents of rational choice theory overstep the mark when they assume that all forms of behavior (or indeed any forms) follow this rational model.

The opposition comes from an ethical perspective that rejects the reductionist approach and from the practical perspective that argues that such pre-conditions as 'perfect information' are in themselves impossible to obtain and may in any case be undesirable (Simon, 1956). In the current case, given the 
presence of modernized elements such as telecommunications and computerization in the election process, it would be expected that aspects of consumer behavior in communicating a political message would also be evident. Consumer behavior discourse and methods have been relocated from the world of business and commerce for this purpose. Models of consumer behavior generally posit an eclectic paradigm in which diverse elements may have an influence on an individual consumption decision. These elements might include personal experience, bias, the influence of family members and peer groups and the like. Since attempts have been made over the past decade to some extent to market political parties as if they were competing brands, the question of whether there is evidence of the success of such attempts has become a worthy one for scholarly investigation. In other words, it would appear that behavior can be mediated by external stimuli in addition to or instead of the calculation that might be made concerning voting according to a pure version of the rational choice theory. As Foucault once observed, voting is a kind of action, which then requires another action from the government (Foucault, 1990). It is, therefore, part of an ongoing interaction in which future events and implications cannot be fully predicted. As such, it explains recent Thai politics quite well. In early history, Thai society consisted of only two classes of people, i.e. Chao (nobles) and Phrai (commoners and slaves) (Kasetsiri, 1995). It was only in the reign of King Rama V that slavery was abolished and Thai society moved towards the tripartite Chao-civil servants-citizen system. Thai students were sent to Europe to undergo Western education and gain experience of the administrative governing system, which could then be introduced into national development processes and help bring about the 1932 political reform (2475 B.E. First Thai Constitution). Owing to inherited norms, values and cultural practices, leadership plays a vital role in Thai families and society. Thai people are taught to respect elderly people and that arguing or expressing opinions (especially from a junior position) may be seen as impolite.

Decision-making is usually made by the head of the family or by temple seniors or reputable people in society, which has been replicated in the foundation of hierarchical local administrations throughout the country. These leaders are accepted for being trustworthy in their ideology and expected to bring in wealth and development to the societies where they belong. Strong leaders have power and connections in both economic and social contexts. Deference is treated as a valuable cultural feature. These underlying political beliefs in Thai society have for decades influenced the way that people have voted in elections and this is reflected in the degree of regional voting variations, since local or regional preferences are developed through extensive personal connections. However, a revolution in political communications has taken place since the 2001 election that saw the debut of the Thai Rak Thai party, the first party to attempt to become a mass membership party and to represent a distinctive ideology and manifesto of policies (outside of the Communist Party of Thailand and some smaller parties limited in ambition and sometimes, indeed, criminalized). The development of this policy and ideology was based in part on an extensive program of focus groups and other forms of research and policy development that had previously been employed successfully by the campaigns of Bill Clinton and Tony Blair (Anurit and Bisonyabut, 2005). What difference, if any, has this evolution made to Thai electoral communications? This study aims to explain, to some extent, the voting patterns of the 2007 General Election as far as data are available as they were influenced by human and non-human factors, and the message reception of various channels with a view to determining effective means of policy communication to the public, and contributing to the democratic development of Thailand.

\section{Background to the 2007 Election}

Since the 1932 Revolution, Thailand has experienced sporadic periods of democracy, having had 27 prime ministers, 17 constitutions and 23 elections. The General Election on December 23, 2007 was held about a year after the September 19, 2006 military coup that took over the country's administration and abolished the 1997 so-called People's Constitution (since this outlawed such actions as military coups). Martial law was imposed across the country. ${ }^{1}$ Some of the important political events that occurred, such as the disbanding of the Thai Rak Thai Party (TRT) by the Constitutional Court, its reconstitution as the People's Power Party (PPP) and the banning of 111 former executives of TRT from engaging in political activities for five years by the Constitutional Court, had obvious impacts on the ability of Thai voters to choose the candidates they would prefer. The 1997 constitution was replaced by a 2007 version (forced through by a referendum held under conditions of martial law and without an alternative being offered)

\footnotetext{
${ }^{1}$ Martial law is permanently in place in various parts of Thailand, notably in the border provinces and provinces where many migrant workers are licensed to live and work. Generally, the provisions of martial law are not put into practice but remain available to military leaders at their discretion.
} 
and the General Election then announced for December 23, 2007. Important changes in the system employed were introduced, including changes in the voting system, as a result of the new Constitution. It redrew the electoral units from 400 constituencies, which then had one elected member each, to 157 constituencies having not more than three members each. The 76 provinces were classified into eight groups and each group was scheduled to have ten members, for a total of 80 party-list members. The 2007 General Election provided 480 members (MPEs) compared to 500 in the previous parliament. Successful party-list members (MPPs) were calculated based on the percentage of nationwide votes. In other words, MPPs were added to directly elected MPEs based on national support for the parties for which they stood (Government Public Relations Department, 2009).

Before the 1997 constitution, the Ministry of the Interior was the body that organized national and local elections. Subsequently, the Election Commission of Thailand (ECT), which was established on June 9, 1998 as an independent statutory body in charge of elections, has assumed this responsibility. The ECT consists of a Chairperson and four other commissioners appointed by His Majesty the King on the advice of the Senate, with a non-renewable term of seven years of service. The Secretary General is responsible for the day-to-day operation of the institution and its provincial offices. The scope of its power is to organize the elections of members of the House of Representatives and the Senate, as well as the election of members of local assemblies and local administrators. The bi-cameral system of government in Thailand is supported by a network of local democratic assemblies at the provincial and local levels. Among the powers and duties of the ECT is the need to determine a measure to control any donation of money, assets or other benefits contributed to a political party, as well as the disbursement of public funds, electoral expenditure and the inspection of political parties' accounts, including control of any payment or receipt of money related to voting (Organic Act on the Election Commission, B.E. 2541 (1998)). The democratic process means people use their ultimate power in determining the administrative direction of the country through the election of representatives into parliament and other administrative bodies. A variety of scholars have written about the benefits of democracy over autocracy in organizing a modern state because of the complexity of allocating scarce resources in cases of opposing claims - the democratic process means that government has to be wise in allocating those resources in line with how people have voted and, if they fail to do so appropriately (or are perceived to have failed to do so), then the electorate will vote for an opposing party or parties at the next opportunity they have to do so.

The tyranny of the majority, the ochlocracy identified by Plato and warned of by Mill (2005) is overcome, with more or less success, by the various institutional checks and balances which limit the power of the executive in different ways (we follow the definition of Dunn, 2006). For an effective democracy to thrive, it is believed that an independent judiciary, bureaucracy and media are required. These ideas have been most influentially enshrined in the Constitution of the USA. Communication is, clearly, of critical importance in all of these processes of articulating varying viewpoints and encouraging people to vote for those which most closely align with their interests, ideology and values (in which ideology, following Althusser, is defined as the 'representation of the imaginary relationship of individuals to their real conditions of existence (Althusser, 2001). Democratic systems require communication between political parties and voters so that the latter are aware of what the former offer. Historically, most such communication has been one-way in nature with parties or individual candidates issuing messages in a variety of formats to persuade people to vote for them or to vote against their political opponents. Advertising is known to be effective, yet the exact way in which that effectiveness occurs is not properly established (e.g. Broadbent, 2008). More recently, political advertising has in some cases taken on a more interactive nature, with political parties willing (at least to some extent) to listen to what voters have to say about various policies and political positions and to incorporate some of that feedback into their manifestoes. In particular, the successful presidential campaigns in the USA of Bill Clinton and the general election success of the Labor party under Tony Blair in the UK are associated with this approach (Ingram and Lees-Marshment, 2002; Lees-Marshment, 2005).

These campaigns featured heavy use of focus groups, in which groups of individuals drawn from important demographic groups were placed together and encouraged to discuss possible policies on a range of different issues. Such an approach was also tried in Thailand by TRT strategists under former Prime Minister Thaksin Shinawatra. TRT subsequently achieved unprecedented electoral success in Thailand, being the first democratically elected party to serve a full term, the first to be re-elected, the first to maintain a parliamentary majority throughout its term and other records. This took place under a longstanding tradition of vote-buying throughout Thailand in elections, in which a general lack of political 
ideology at the party and candidate level, combined with the influence exerted by a variety of extrajudicial individuals in the Kingdom and the (eminently understandable) cynicism with which people treated the promises made by politicians, meant that the distribution of bribes had come to be thought of as the principal means of winning elections. Irrespective of the mass media campaigns attempting to persuade people of the opposite, TRT did a great deal to remove these problems by standing on policy manifestoes and employing party discipline as widely as was possible. Despite the victory of money and influence politics represented by the post-coup installation of the Abhisit regime in 2008, the trend has been to continue with the TRT approach, no doubt in part because of its enormous success and costeffectiveness. It is a matter of genuine academic interest to determine how to further this process, since it is likely to increase the ability of Thai voters to be represented by those who are pledged to furthering their interests. Of the non-partisan steps that might be taken towards such an outcome, the study of political communications is one of the more important because it relates to efficiency of scarce resources and the improvement in commitment towards the political settlement.

As a part of that approach, factors influencing voters and their voting intentions - including ranking in importance human factors (self, family members, canvassers and community leaders) and non-human factors (current social trends, political policies, political campaign activities and political advertisements) - were investigated. Questionnaire research was employed so as to determine whether demographic factors may be used to predict voting intentions and, if so, which factors they might be. The relative importance of different channels of political communication was also investigated, with a view to linking (in of course a non-causal relationship) the importance of different channels, demographic factors and voting intentions. Regional variations added an additional level of possible understanding of the various dynamic factors involved. This information may then be used to feed into decisions concerning the relative propensity to use above the line (i.e. mass media) or below the line (i.e. aimed directly at specific individuals) forms of communications and hence the impact upon communication strategies overall and the use of communication budgets (Laohakosol and Walsh, 2010). This is, in some senses, therefore, a type of action research aimed at provoking certain activities determined as being preferable to the alternatives, in addition to aspiring to have academic value in its own right.

\section{Methodology}

This study was conducted as part of a larger framework for doctoral research concerning the roles of communication and marketing within the Thai political system and its processes. The methodology used for the results reported in this paper involved a combination of both quantitative and qualitative approaches. The quantitative portion of the study took the form of a face-to-face questionnaire interview administered by trained interviewers. Both open-ended and closed questions were included on an instrument that was designed in the light of previous studies (in Thailand and elsewhere) and involving both expert opinion and a pilot study. The interviews were conducted in Thai and subsequently interpreted into English for the purpose of analysis. Four locations were selected to represent the different regions of Thailand. These were Bangkok, Chiang Mai, Phuket and Khon Kaen. These four provinces were selected not only in terms of being leading contributors to overall national revenue (as measured by Gross Provincial Product) but also with respect to the principle of maximum diversity. Although samples in the individual locations were selected on a random basis, interviewers were instructed to observe the same principle in approaching potential respondents (List, 2004). In this sense, both rural and urban locations were selected as the place for conducting interviews. Total sample sizes were as follows:

Table 1: Sample Size

\begin{tabular}{ll}
\hline Location & N \\
\hline Bangkok & 106 \\
Chiang Mai & 106 \\
Phuket & 105 \\
Khon Kaen & 106 \\
Total & 423 \\
\hline Source: original research
\end{tabular}

Source: original research

Data was collected during the period of February-May, 2010. A pilot study of 35 interviews was conducted in February and revealed no particular problems in terms of understanding or answering questions. The reliability co-efficient (Cronbach's alpha) of the pilot study was 0.7502 and this increased 
to 0.7800 for the full sample. The size of the sample is sufficient to meet the requirements of the Yamane formula, although caution should be taken with respect to reporting the results for sub-sets of the overall sample. The sample achieved, however, was slightly uneven and did not match the overall population of Thailand in some important respects.

Table 2: Age and Gender Breakdown of the Sample

\begin{tabular}{lll}
\hline Age group & Male (\%) & Female (\%) \\
\hline $18-24$ & 28.8 & 25.0 \\
$25-34$ & 30.4 & 37.5 \\
$35-44$ & 15.7 & 15.5 \\
$45-54$ & 12.6 & 12.9 \\
$55-64$ & 9.9 & 7.8 \\
$65+$ & 2.6 & 1.3 \\
$\mathrm{~N}$ & 191 & 232 \\
\hline
\end{tabular}

Source: original research

The sample is somewhat biased towards younger people and towards those with higher levels of education. However, such people are more likely to be attuned to the modern methods of communication, which is the principal topic of investigation in this case. Unfortunately, although care was taken to divide the sample between rural (47.3\%) and urban areas (52.3\%), very few farmers ('agriculturists') were interviewed and this suggests some possible bias in the results.

Table 3: Employment and Income Status of Sample

\begin{tabular}{|c|c|c|c|}
\hline Employment & \%age & Average monthly income & \%age \\
\hline Agriculturists & 3.3 & $<5,000$ baht & 21.3 \\
\hline Entrepreneurs/Traders & 12.5 & $5,001-15,000$ baht & 45.6 \\
\hline $\begin{array}{l}\text { Government/State } \\
\text { Workers }\end{array}$ & 19.6 & $15,001-25,000$ baht & 14.7 \\
\hline Contract Workers/Laborers & 10.2 & $25,001-35,000$ baht & 7.1 \\
\hline Company Employees & 22.5 & $35,001-45,000$ baht & 4.7 \\
\hline Freelancers/Skilled Workers & 5.7 & $45,001+$ baht & 6.6 \\
\hline Students & 18.4 & & \\
\hline Unemployed & 2.6 & & \\
\hline Others & 5.2 & & \\
\hline $\mathrm{N}$ & 423 & & 423 \\
\hline
\end{tabular}

Source: original research.

\section{Analysis and Results}

Respondents were asked to rank the sources of election message by media channel (top 5 cut off point) and people/institution ranking. The results are shown in Table 4 below.

Table 4 A: General Election 2007 Media Channel Ranking

\begin{tabular}{|c|c|c|c|c|c|}
\hline Channel & Bangkok & $\begin{array}{c}\text { Chiang } \\
\text { Mai }\end{array}$ & $\begin{array}{l}\text { Khon } \\
\text { Kaen }\end{array}$ & Phuket & Total \\
\hline 1. TV & 1 & 1 & 1 & 1 & 1 \\
\hline 2. Cable TV/satellite & 5 & 4 & 4 & 4 & 4 \\
\hline 3. Radio & 4 & 2 & 3 & 5 & 3 \\
\hline 4. Mobile vehicles & 3 & 0 & 0 & 1 & 5 \\
\hline 5. Mobile Phone & 0 & 0 & 0 & 0 & 0 \\
\hline 6. Internet & 0 & 5 & 5 & 0 & 0 \\
\hline 7. Poster/Printed Materials & 2 & 3 & 2 & 2 & 2 \\
\hline
\end{tabular}


Television ranks first as always because it reaches every household. However, it remains an expensive medium for advertisers, even though the ECT is willing to help sharing the cost of those campaigns, which aim only at persuading people to come out to vote. Posters and printed materials are still effective visual aids available at a reasonable cost. Radio comes third, although people in Bangkok and Phuket accord it a lower ranking. By 2007, cable/satellite TV had started to play a more important role in Thai communities with singing competitions, perpetual live coverage of panda bears and similar programs being particularly popular. This has meant that the traditional fish bone antennas have been disappearing from the landscape. Mobile vehicles carrying posters and microphones are still believed to be effective and can be used in narrow urban streets (sois) and focus on specific residential areas quite regularly. It is interesting to observe that people in Chiang Mai and Khon Kaen get election messages via internet media. It could be explained that these two cities have well-developed universities and numerous foreign professionals and, so, access to technology is both necessary and comparatively easy (although not unproblematic). Both areas are also magnets for internal labor migration, on both a temporary (and occasionally seasonal) or permanent basis. Regarding personal and institutional sources of information, the pattern is the same for Bangkok and Chiang Mai, i.e. political parties and their candidates rank first. However, the pattern in Khon Kaen resembles the results for the country as a whole, that is, relatives/friends are the main source of information.

Table 4 B: People/Institution Ranking

\begin{tabular}{lccccc}
\hline Channel & Bangkok & Chiang Mai & $\begin{array}{c}\text { Khon } \\
\text { Kaen }\end{array}$ & Phuket & Total \\
\hline 1. Relatives/Friends & 2 & 2 & 1 & 1 & 1 \\
2. Canvasser & 4 & 4 & 3 & 2 & 3 \\
3. Political Parties/Candidate & 1 & 1 & 2 & 3 & 2 \\
4. ECT & 3 & 3 & 4 & 4 & 4 \\
\hline
\end{tabular}

Source: original research.

Further analysis of the results via cross-tabulations revealed a number of significant distributions (according to chi square tests) for the demographic variables of age, type of residential location, occupation and marital status. These tend to support the use of new media for younger and more highly educated people, including those in urban locations, while the traditional media channels were more closely associated with people in other demographic categories. Similar patterns were observed with respect to expectations of future media consumption in terms of politics (see below).

Table 5: Expectation for the Next Election Media Channel Ranking

\begin{tabular}{llllll}
\hline Channel & Bangkok & $\begin{array}{l}\text { Chiang } \\
\text { Mai }\end{array}$ & $\begin{array}{l}\text { Khon } \\
\text { Kaen }\end{array}$ & Phuket & Total \\
\hline 1. TV & 1 & 1 & 1 & 1 & 1 \\
2. Cable TV/satellite & 6 & 5 & 4 & 4 & 4 \\
3. Radio & 3 & 4 & 3 & 5 & 3 \\
4. Mobile Vehicle & 3 & 2 & 2 & 3 & 7 \\
5. Mobile Phone & 6 & 6 & 5 & 6 & 5 \\
6. Internet & 5 & 6 & 6 & 7 & 6 \\
7. Poster/Printed Materials & 2 & 3 & 7 & 2 & 2 \\
\hline Sour
\end{tabular}

Source: original research.

For overall results of this selected group, it is interesting to see that people still expect to receive messages from the same media channels that they did for the 2007 general election, as reflected in the ranking of media in positions from 1-4, with mobile phones and the internet coming into play in positions 5 and 6, thus pushing mobile vehicle down to the bottom ranking. It appears that, with this sample of respondents, traditional media still appear to be effective channels for distribution; while there is scope for new media such as mobile phones and the internet, which, with various other social networks, also exhibit opportunities for growth. The mobile penetration rate has grown rapidly, despite the continued 
unavailability of some 3G services. It is common for a customer to have more than one mobile phone number. The usage of non-voice functions such as SMS, MMS and CHAT is adding more and more revenue for telephone operators but the cost is still high compared to the voice rate. Nevertheless, the use of these media is developing in terms of personal communications and advertising. Internet usage in Thailand is in a growth stage too, i.e. more than $30 \%$ for the past three years, although the penetration rate is not as high as for mobile phones. Availability of affordable technology and the computer literacy rate are often included among the constraining factors in this regard. It is apparent that the mix of media consumed by Thai people and their methods of consumption are changing and communication strategies will need to evolve in order to keep track of these changes.

\section{Conclusion}

With the rules and regulations imposed by the ECT and the growth of global state-of-the-art technology, political parties and candidates have to adjust their strategies in communicating to voters, through both traditional and new media as they may reach different target groups and with different degrees of success. Competition does rest upon what is said and how it is said in each channel of media and each demographic target group in the different geographical locations, with their characteristic political configurations. The allocation of expenditure budgets in political campaigns is to be entirely planned, i.e. an integrated marketing communication mix of Above the Line and Below the Line programs designed specifically for each region and nationwide. Of course, more comprehensive and in-depth studies may be helpful in developing further good communication campaign management without violating ECT rules, such as are available in other countries in which large-scale political marketing communications is common and widely accepted. Further research is being undertaken to broaden and deepen the understanding of the interaction between electoral politics in Thailand and methods of communication. As the results reported here show, it is possible to distinguish between different media channels and distinct demographic groups and, therefore, it is possible to move towards tailoring media communications that deal with policy issues of more interest to the people receiving them. Up to and including the 2007 election, Thai voters have been voting in accordance with what models of consumer behavior would predict: that is, they take into account environmental and cultural influences and variables to which they are exposed. They have not, it appears, been able to follow a rational choice model of behavior as a whole both because their ideological concerns have not been addressed and because, where ideology has informed policy formulation, it has not been accurately communicated to them.

\section{References}

Althusser, L. (2001). Ideology and ideological state apparatus (Notes toward an investigation). In L. Althusser. Lenin and philosophy and other essays (85-127). New York, NY: Monthly Review Press.

Anurit, P. \& Bisonyabut, T. (2005). Below the line government: An initial investigation into Thai Rak Thai political marketing. In J. Walsh (Ed.), the globalization of executives and economies: Evidence from Thailand (156-68). Oxford: Chandos Publishing.

Broadbent, T. (2008). Does advertising grow markets? More evidence from the United Kingdom. International Journal of Advertising, 27(5), 745-770.

Downs, A. (1957). An economic theory of democracy. New York, NY: Harper and Row.

Dunn, J. (2006). Setting the people free: The story of democracy. London: Atlantic Books.

Foucault, M. (1990). Politics, philosophy, culture: Interviews and other writings, 1977-84. London and New York, NY: Routledge.

Government Public Relations Department (PRD). (2009). the Election of Members of the House of Representatives (August 21). Retrieved from: http://thailand.prd.go.th/democracy/view_democracy.php?id=4374.

Ingram, P. \& Lees-Marshment, J. (2002). The Anglicization of political marketing: How Blair out-marketed Clinton. Journal of Public Affairs, 2(2), 44-56.

Kasetsiri, C. (1995). Thai political history. Bangkok: Dokya Publishing House (in Thai).

Laohakosol, W. \& Walsh, J. C. (2010). Factors influencing voting intentions for members of the Thai House of Representatives and implications for the integrated marketing communications mix. Phuket Rajabhat University: ICIMM Proceedings.

Lees-Marshment, J. (2005). The marketing campaign: The British general election of 2005, Journal of Marketing Management, 2, 9/10, 1151-1160. 
List, D. (2004). Maximum variation sampling for surveys and consensus groups. Adelaide: Audience Dialogue. Retrieved from: www.audiencedialogue.org/maxvar.html

Mill, J. S. (2005). On liberty. New York, NY: Cosimo Classics.

Nawigamune, A. (1999). Siam printing. Bangkok: River book Publishing House (in Thai).

Nelson, M. (2009). Electoral rules concerning the House of Representatives in the 2007 Thai constitution. Working Paper No.104. City University of Hong Kong: Southeast Asia Research Centre.

Organic Act on the Election Commission, B.E. 2541. (1998). retrieved from: http://www.ect.go.th/english/files/about\%20ect/Organic\%20Act\%20on\%20the\%20Election\% 20Commission.pdf

Simon, H.A. (1956). Rational choice and the structure of the environment. Psychological Review, 63(2), 129-38.

Zafirovski, M. (1998). Socio-economics and rational choice theory: Specification of their relations. Journal of Socio-Economics, 27(2), 165-205.

\section{Appendix 1:}

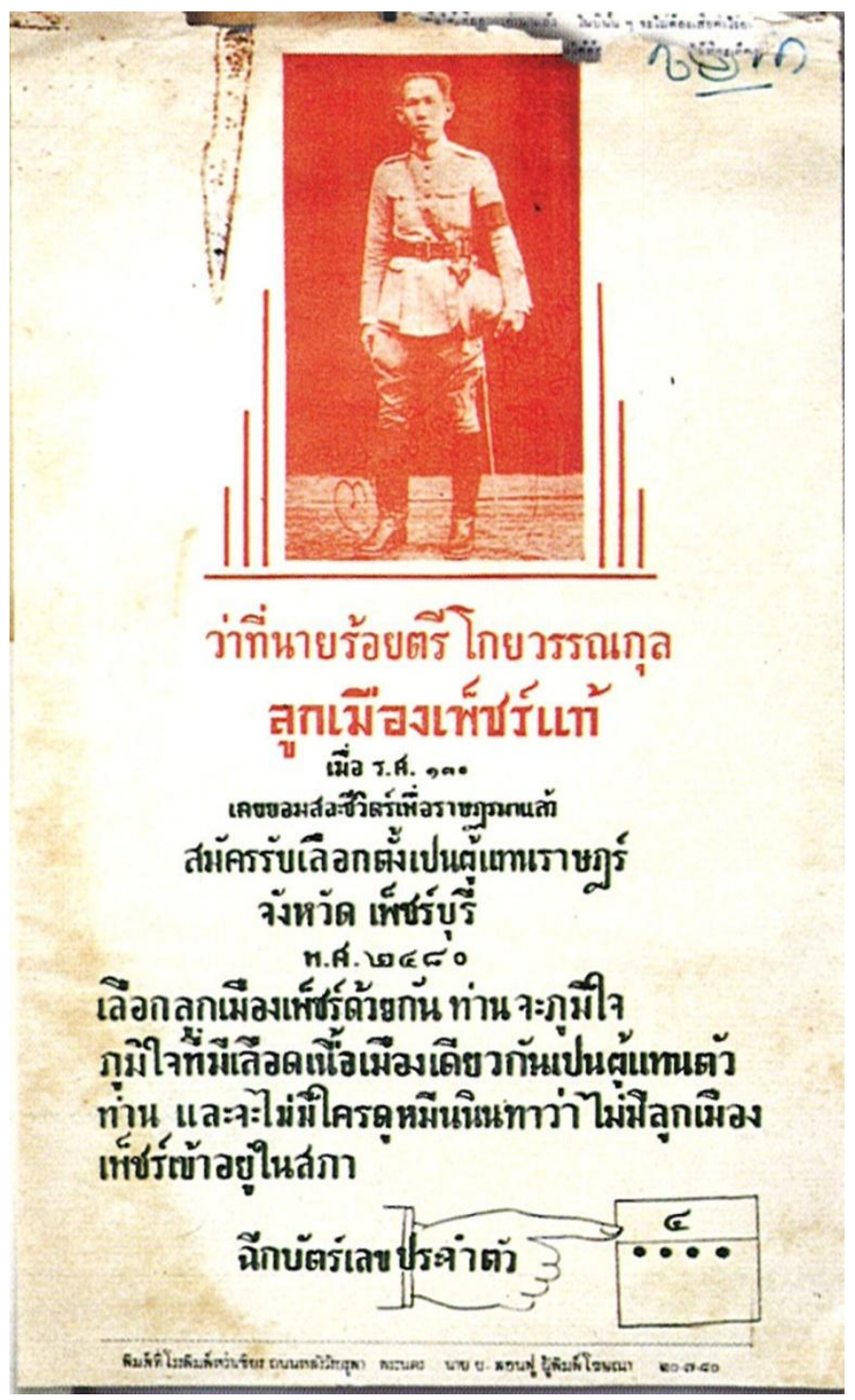

Source: Nawigamune, A. (1999). Siam Printing, Bangkok: River book Publishing House (in Thai). 